\begin{tabular}{|c|c|c|}
\hline \multirow{4}{*}{$\begin{array}{r}\text { Case Reports in } \\
\text { Gastroenterology }\end{array}$} & \multirow{2}{*}{\multicolumn{2}{|c|}{ Case Rep Gastroenterol 2019;13:481-486 }} \\
\hline & & \\
\hline & $\begin{array}{l}\text { DOI: } 10.1159 / 000504565 \\
\text { Published online: November 21, } 2019\end{array}$ & $\begin{array}{l}\text { (c) } 2019 \text { The Author(s) } \\
\text { Published by S. Karger AG, Basel } \\
\text { www.karger.com/crg }\end{array}$ \\
\hline & $\begin{array}{l}\text { This article is licensed under the } \mathrm{Cr} \\
\text { International License (CC BY-NC) (ht } \\
\text { Usage and distribution for commercial }\end{array}$ & $\begin{array}{l}\text { nons Attribution-NonCommercial } 4.0 \\
\text { ger.com/Services/OpenAccessLicense). } \\
\text { uires written permission. }\end{array}$ \\
\hline
\end{tabular}

\title{
Chylous Ascites Accompanying Internal Hernia after Total Gastrectomy with Roux-en-Y Reconstruction
}

\author{
Ryota Koyama Yoshiaki Maeda Nozomi Minagawa Toshiki Shinohara \\ Tomonori Hamada \\ Department of Gastrointestinal Surgery, Hokkaido Cancer Center, Sapporo, Japan
}

\section{Keywords}

Chylous ascites · Gastric cancer · Total gastrectomy $\cdot$ Roux-en-Y reconstruction · Internal hernia · Mesenteric defect - Laparoscopic surgery

\begin{abstract}
We report the case of a 69-year-old man with a history of esophagogastric junction cancer (Barrett's esophageal cancer; pT1b [SM], N0, M0, pStage IA) that was surgically resected 2 years prior to the present episode. Recurrence was not observed during follow-up. Following complaints of dysphagia and abdominal pain, computed tomography revealed signs of internal hernia. Thus, laparoscopic exploration was performed. Intraoperatively, accumulation of chylous ascites accompanying the internal hernia through the jejunojejunostomy mesenteric defect was observed, which was successfully treated with laparoscopic hernia reduction and defect closure by sutures without intestinal resection. Here, we discuss the case and report that along with previous studies, our study suggests that chylous ascites might be a reliable sign of intestinal viability for herniated intestines.




\section{Case Reports in Gastroenterology}

Case Rep Gastroenterol 2019;13:481-486

DOI: $10.1159 / 000504565$

(c) 2019 The Author(s). Published by S. Karger AG, Basel www.karger.com/crg

Koyama et al.: A Case of Internal Hernia after Roux-en Y Reconstruction Causing Chylous Ascites

\section{Introduction}

Chylous ascites (milky ascites) is defined as an intraperitoneal accumulation of lymphatic fluid rich in triglycerides derived from the intraabdominal lymphatic system [1]. While the frequent causes of chylous ascites are due to the abdominal malignancy and traumatic (including surgical) damage to the lymphatic system, it is occasionally observed during surgery for intestinal obstruction, mainly small intestinal volvulus [2].

Herein, we report a case of chylous ascites accompanying internal hernia with the defect between the Roux-en-Y limb anastomotic site and the mesentery (jejunojejunostomy mesenteric defect). This condition was successfully treated with laparoscopic hernia reduction and defect closure by sutures without intestinal resection.

\section{Case Presentation}

The patient was a 69-year-old man with a history of esophagogastric junction cancer [Barrett's esophageal cancer; pT1b (SM), N0, M0, pStage IA] that was treated 2 years prior to the present episode by total gastrectomy with lower esophageal resection and Roux-en-Y reconstruction (retrocolic route) and cholecystectomy. The postoperative course was uneventful, and no adjuvant therapy was provided. However, during the follow-up, asymptomatic left renal cell carcinoma was detected; hence, robot-assisted left partial nephrectomy was performed 3 months postoperatively. Since then, no sign of recurrence of left renal cell carcinoma was detected. Other medical history included hypertension, for which medication was provided, and appendectomy at the age of 20 years.

The patient started complaining of dysphagia and abdominal pain 1 week prior to admission. Because the abdominal pain worsened 1 day prior to admission, he was transferred to the emergency department of our hospital.

On admission, his height was $166 \mathrm{~cm}$ and his weight was $54 \mathrm{~kg}$ (85 kg during esophagogastric junction cancer surgery 2 years ago). His vital signs were as follows: blood pressure, $147 / 101 \mathrm{~mm} \mathrm{Hg}$; heart rate, 63 beats $/ \mathrm{min}$; body temperature, $36.5^{\circ} \mathrm{C}$. The abdomen was soft and flat, without any tenderness or palpable mass. Moreover, his complete blood count and serum chemistry results were within normal limits. His carcinoembryonic antigen level was slightly elevated $(9.8 \mathrm{ng} / \mathrm{mL})$ but had not increased during the follow-up period of 2 years. Additionally, his cancer antigen 19-9 level was within normal limits. Enhanced abdominal computed tomography (CT) revealed a regional edema in the mesentery of the small intestine and local narrowing of the jejunal branch of the superior mesenteric artery (Fig. 1a, b). The superior mesenteric vein was completely blocked (Fig. 1c). The mesenteric vessels appeared to be whirled, suggesting volvulus of the small intestine at the proximal region (Fig. 1a). The superior mesenteric artery appeared to be evident, and the small intestinal walls were well-enhanced, indicating their viability. A small amount of ascites was observed. Nonetheless, no sign of cancer recurrence was observed elsewhere. The CT findings suspected internal hernia; hence, on the second day of admission, he agreed to undergo laparoscopic exploration.

The patient was placed in the supine position. Pneumoperitoneum was created using carbon dioxide at $8 \mathrm{~mm} \mathrm{Hg}$. A 12-mm-long trocar was inserted through the umbilicus for laparoscopy. In addition, two 5-mm-long trocars were separately placed in the right upper and lower quadrants for the surgeon. For the assistant surgeon, 5-mm-long trocars were placed in the left lower quadrant. The greater omentum was observed to be broadly adhered to the 


\section{Case Reports in Gastroenterology}

Case Rep Gastroenterol 2019;13:481-486

DOI: $10.1159 / 000504565$

(c) 2019 The Author(s). Published by S. Karger AG, Basel www.karger.com/crg

Koyama et al.: A Case of Internal Hernia after Roux-en Y Reconstruction Causing Chylous Ascites

abdominal wall; hence, initially, adhesiolysis was performed. The small intestine, which had a white edematous appearance in its mesentery, was herniated through the jejunojejunostomy mesenteric defect (Fig. 2a). Chylous ascites was observed mainly in the left paracolic gutter and surrounding areas (Fig. $2 \mathrm{~b}$ ). The herniated small intestine, measuring 1-2 m, was reduced (Fig. 2c, d). After successful laparoscopic reduction of the hernia, a large defect with a collection of chylous ascites appeared (Fig. 2e). The defect was subsequently closed using interrupted sutures (Fig. 2f). No sign of intestinal necrosis was observed; thus, intestinal resection was not required. The operation time was $71 \mathrm{~min}$, with $5 \mathrm{~mL}$ blood loss. The postoperative course was uneventful. He started eating on postoperative day (POD) 2 and discharged on POD 13. No symptoms suspecting internal hernia recurred 3 months postoperatively.

\section{Discussion}

Chylous ascites typically develops because of the disruption of the abdominal lymphatic system. It is frequently caused by neoplasms (especially malignant lymphoma) and cirrhosis in developed countries and chronic infections such as tuberculosis and filariasis in developing countries [1].

Lymphatic drainage from the abdominal organs converges at the intestinal trunk and further at the chyle cistern, which aids in the flow of lymphatic fluid upwards to form the thoracic duct [3].

Chylous ascites occurs via the following three mechanisms [4]: obstruction of lymph flow by a neoplastic cause leading to leakage from the lymphatic system; exudation of lymph from the lymphatic system into the peritoneal cavity; or direct damage to the lymphatic vessels by trauma or surgery.

However, coexistence of chylous ascites and intestinal obstruction is rare, with only few case reports are published to date [2]. Among such studies, Akama et al. [2] reported that chylous ascites indicates intestinal viability because when the literature was reviewed, it was observed that intestinal resection was not required when chylous ascites was found intraoperatively. The indication of intestinal viability by chylous ascites can be explained hypothetically as follows. First, lymph production requires an unobstructed arterial flow. Second, with a lowpressure system, veins and lymphatics are initially occluded by intestinal volvulus, whereas with a high-pressure system, the artery remains unobstructed; thus, in case of chylous ascites, the pressure could be between the two extremes.

Abdominal paracentesis is performed for direct diagnosis. Ascites fluid typically appears as turbid and milky, and its triglyceride levels can be $>200 \mathrm{mg} / \mathrm{dL}$ [5]. Meanwhile, CT is a common and useful imaging modality; it can detect intraabdominal lesions causing chylous ascites. CT revealed that the ascites had a density similar to that of water; however, it excludes hemoperitoneum, which shows a high CT value especially in a trauma setting [5].

Roux-en-Y reconstruction, an intestinal reconstruction method, is the standard procedure for total gastrectomy. However, this method inevitably creates novel intraabdominal defects, such as Petersen's, jejunojejunostomy mesenteric (as in our case), and transverse colon mesenteric (only in case of the retrocolic route) defects, which potentially cause internal hernias. A recent study involving 6,474 patients who had undergone gastrectomy for gastric cancer reported that the rate of internal hernia was $1.7 \%$, and of those, $86 \%$ of patients had undergone Roux-en-Y reconstruction [6]. The most common were jejunojejunostomy mesenteric defects, accounting for $53 \%$ of patients who had developed internal hernia. 
Postoperative internal hernia after Roux-en-Y reconstruction is more frequent in cases of laparoscopic surgery for reducing adhesion and mobile intestines [7]. Consequently, an antecolic route is routinely selected for reducing the number of defects (i.e., transverse colon mesenteric defect) $[7,8]$. However, postoperative loss of body weight results in the loss of mesenteric fat, leading to defect enlargement $[9,10]$. The broadly accepted consensus is closing the potential defect by sutures $[6,11-13]$.

In the present case, the patient developed internal hernia through the jejunojejunostomy mesenteric defect, which was not closed during the initial gastrectomy for gastric cancer. Although internal hernia might be attributed to considerable weight loss, the present condition could have been prevented if the defect was closed. This complication may become fatal when the diagnosis and surgical intervention are delayed. However, as shown in our case, the chylous ascites found intraoperatively might be a reliable sign that the herniated intestines are viable. Hence, although such cases are rare, surgeons need to always consider that chylous ascites can be one of the indicative signs of intestinal viability.

In conclusion, this case report presents an unusual case of chylous ascites accompanying internal hernia through the jejunojejunostomy mesenteric defect. Along with the previous reports, our study suggests that chylous ascites might be a reliable sign of intestinal viability for herniated intestines.

\section{Statement of Ethics}

The authors have no ethical conflicts to disclose.

\section{Disclosure Statement}

The authors have no conflicts of interest to declare.

\section{Funding Sources}

This work received no funding.

\section{Author Contributions}

R.K. is the primary investigator and contributed to conceptualization, data collection and drafting the manuscript. All authors have read and approved the manuscript for publication.

\section{References}

1 Aalami 0O, Allen DB, Organ CH Jr. Chylous ascites: a collective review. Surgery. 2000 Nov;128(5):761-78.

2 Akama Y, Shimizu T, Fujita I, Kanazawa Y, Kakinuma D, Kanno H, et al. Chylous ascites associated with intestinal obstruction from volvulus due to Petersen's hernia: report of a case. Surg Case Rep. 2016 Dec;2(1):77.

3 Al-Busafi SA, Ghali P, Deschênes M, Wong P. Chylous Ascites: evaluation and Management. ISRN Hepatol. 2014 Feb;2014:240473. 
Koyama et al.: A Case of Internal Hernia after Roux-en Y Reconstruction Causing Chylous Ascites

4 Browse NL, Wilson NM, Russo F, al-Hassan H, Allen DR. Aetiology and treatment of chylous ascites. Br J Surg. 1992 Nov;79(11):1145-50.

5 Cárdenas A, Chopra S. Chylous ascites. Am J Gastroenterol. 2002 Aug;97(8):1896-900.

6 Kang KM, Cho YS, Min SH, Lee Y, Park KB, Park YS, et al. Internal hernia after gastrectomy for gastric cancer in minimally invasive surgery era. Gastric Cancer. 2019 Sep;22(5):1009-15.

7 Hosoya Y, Lefor A, Ui T, Haruta H, Kurashina K, Saito S, et al. Internal hernia after laparoscopic gastric resection with antecolic Roux-en-Y reconstruction for gastric cancer. Surg Endosc. 2011 Oct;25(10):3400-4.

8 Hwang RF, Swartz DE, Felix EL. Causes of small bowel obstruction after laparoscopic gastric bypass. Surg Endosc. 2004 Nov;18(11):1631-5.

9 Takiguchi S, Yamamoto K, Hirao M, Imamura H, Fujita J, Yano M, et al.; Osaka University Clinical Research Group for Gastroenterological Study. A comparison of postoperative quality of life and dysfunction after Billroth I and Roux-en-Y reconstruction following distal gastrectomy for gastric cancer: results from a multiinstitutional RCT. Gastric Cancer. 2012 Apr;15(2):198-205

10 Comeau E, Gagner M, Inabnet WB, Herron DM, Quinn TM, Pomp A. Symptomatic internal hernias after laparoscopic bariatric surgery. Surg Endosc. 2005 Jan;19(1):34-9.

11 Kelly KJ, Allen PJ, Brennan MF, Gollub MJ, Coit DG, Strong VE. Internal hernia after gastrectomy for cancer with Roux-Y reconstruction. Surgery. 2013 Aug;154(2):305-11.

12 Yoshikawa K, Shimada M, Kurita N, Sato H, Iwata T, Higashijima J, et al. Characteristics of internal hernia after gastrectomy with Roux-en-Y reconstruction for gastric cancer. Surg Endosc. 2014 Jun;28(6):1774-8.

13 Kojima K, Inokuchi M, Kato K, Motoyama K, Sugihara K. Petersen's hernia after laparoscopic distal gastrectomy with Roux-en-Y reconstruction for gastric cancer. Gastric Cancer. 2014 Jan;17(1):146-51.

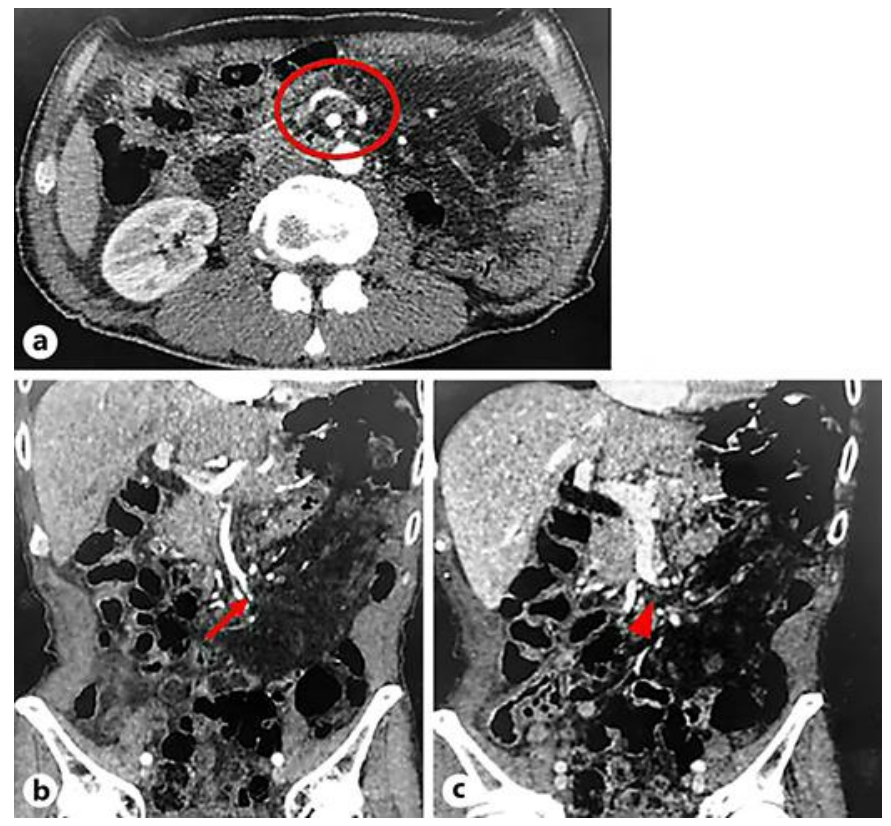

Fig. 1. Computed tomography imaging. a Regional edematous swelling of the small intestine mesentery was observed. The mesenteric vessels appeared to be whirled, suggesting volvulus at the proximal region of the small intestine (circle). $\mathbf{b}$ The jejunal branch of the superior mesenteric artery was locally narrowed but not totally occluded (arrow). c The superior mesenteric vein was completely blocked (arrowhead). 


\section{Case Reports in Gastroenterology}
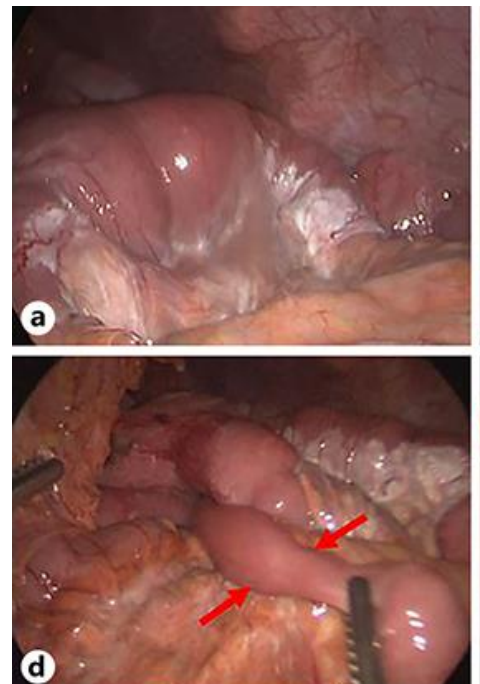

d

Fig. 2. Intraoperative findings. a The small intestine was edematous with milky exudates on the mesentery. b The turbid, milky ascites was observed primarily in the left paracolic gutter and surrounding areas. c, d The herniated small intestine (arrow) measuring 1-2 m, was reduced because of the defect. e The jejunojejunostomy mesenteric defect (circled) with chylous ascites was clearly observed after complete hernia reduction. $f$ The defect was closed by applying interrupted sutures.
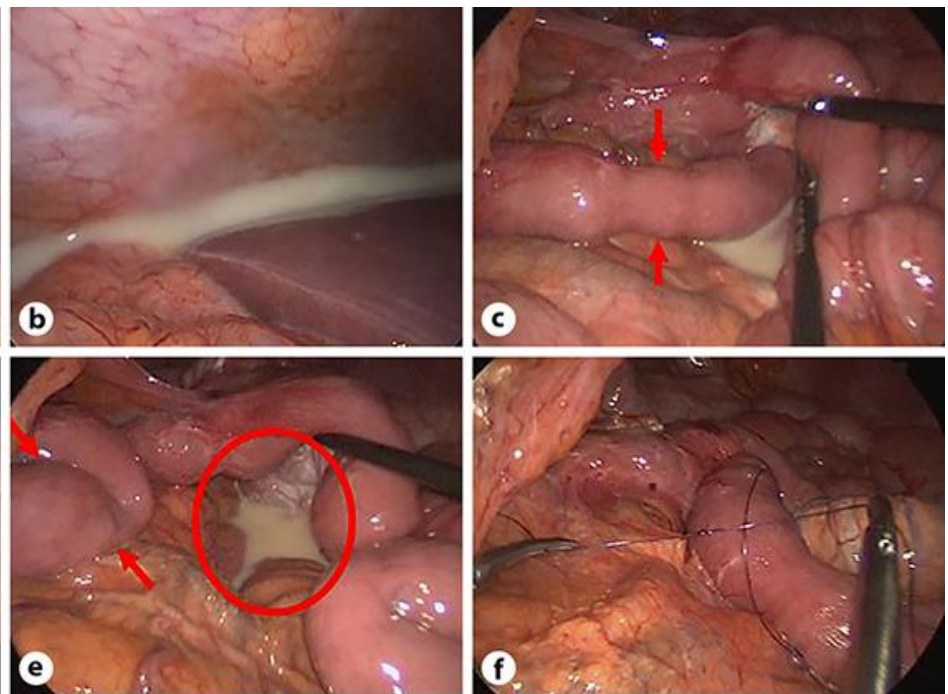

Koyama et al.: A Case of Internal Hernia after Roux-en Y Reconstruction Causing Chylous Ascites

(c) 2019 The Author(s). Published by S. Karger AG, Basel www.karger.com/crg 